\title{
Solitary Intracranial Castleman's Disease, Plasma Cell Variant: A Case Report
}

\author{
A.A. Mallik ${ }^{\text {a }}$ K.C. Katchy ${ }^{a} \quad$ N. Clotan ${ }^{b}$ \\ ${ }^{a}$ Department of Pathology, Al-Sabah Hospital, and ${ }^{\text {b}}$ Department of Neurosurgery, Ibn Sina Hospital, Kuwait
}

\section{Key Words}

Castleman's disease • Dura • Intracranial tumor •

Meningioma

\begin{abstract}
Objective: We report a case of plasma cell variant of Castleman's disease confined to the meninges. Clinical Presentation and Intervention: A 53-year-old woman presented with severe headache lasting a few months, which was insidious in onset but followed a progressive course with associated vomiting, blurring of vision and diplopia. Investigations revealed a dural-based mass that was considered both radiologically and intraoperatively as a meningioma. Total surgical excision of the mass was performed. Histologically, it was a plasma cell variant of Castleman's disease with $\kappa$ light chain restriction. Laboratory investigations and whole body computerized tomography scan showed no significant abnormality. A short course of local radiotherapy was given. The patient is well 2 years after treatment. Conclusion: This report highlights the rarity of solitary intracranial Castleman's disease and the difficulty in radiological and intraoperative diagnosis. Copyright $\odot 2007$ S. Karger AG, Basel
\end{abstract}

\section{Introduction}

Castleman's disease (CD) is a rare lymphoproliferative disorder, which is predominantly intranodal but may also affect other anatomical sites [1]. Two major histological variants, hyaline-vascular and plasma cell types, are recognized [1]. Furthermore, CD may be solitary or multicentric. While the former is usually benign and predominantly of the hyaline-vascular type, the latter is composed mostly of the plasma cell variant and is often associated with systemic manifestations and poor prognosis with a fatal outcome $[2,3]$.

Although there have been reports of central nervous system involvement in multicentric CD [2], solitary intracranial lesions are rare. To the best of our knowledge, only 12 cases of solitary intracranial CD have been reported in the medical literature so far [4-10]. In all cases, it was mistaken both clinically and radiologically as a meningioma.

The objective of this report is to document the first case of a solitary intracranial CD diagnosed in a 53year-old female patient in Kuwait. Histologically, it was a plasma cell variant of $C D$ with $\kappa$ light chain restriction.

\section{KARGER \\ Fax +41613061234 \\ E-Mail karger@karger.ch}

www.karger.com
(C) 2007 S. Karger AG, Basel

1011-7571/07/0163-0226\$23.50/0

Accessible online at:

www.karger.com/mpp
Dr. Anupama Arora Mallik

Department of Pathology, Al-Sabah Hospital

PO Box 4078

Safat 13041 (Kuwait)

Tel. +965 6803473 (M), Fax +965 481 8541, E-Mail anupamamallik@yahoo.co.in 


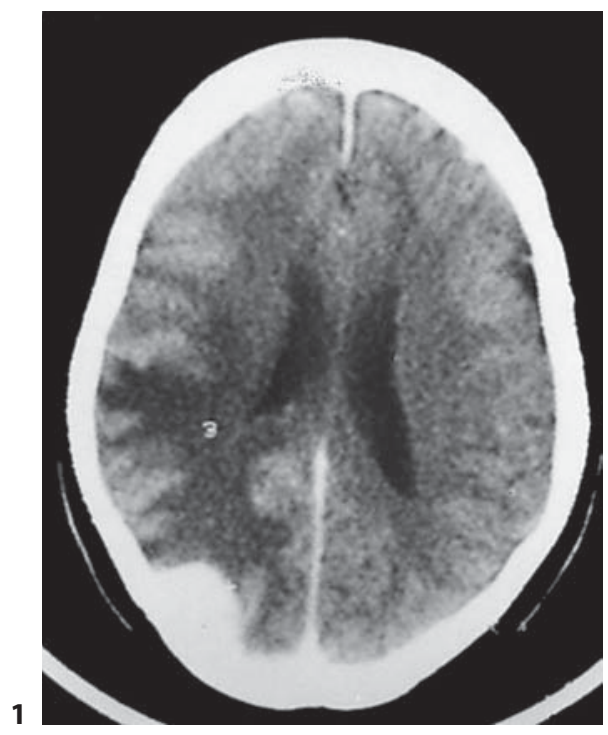

Fig. 1. CT scan with contrast (axial view) of the occipital lobe shows a contrastenhancing well-defined dura-based mass with extensive surrounding edema.

Fig. 2. The lesion comprising lymphoid follicles with germinal centers. HE. $\times 100$.

Fig. 3. The interfollicular area shows sheets of mature-appearing plasma cells. HE. $\times 400$.
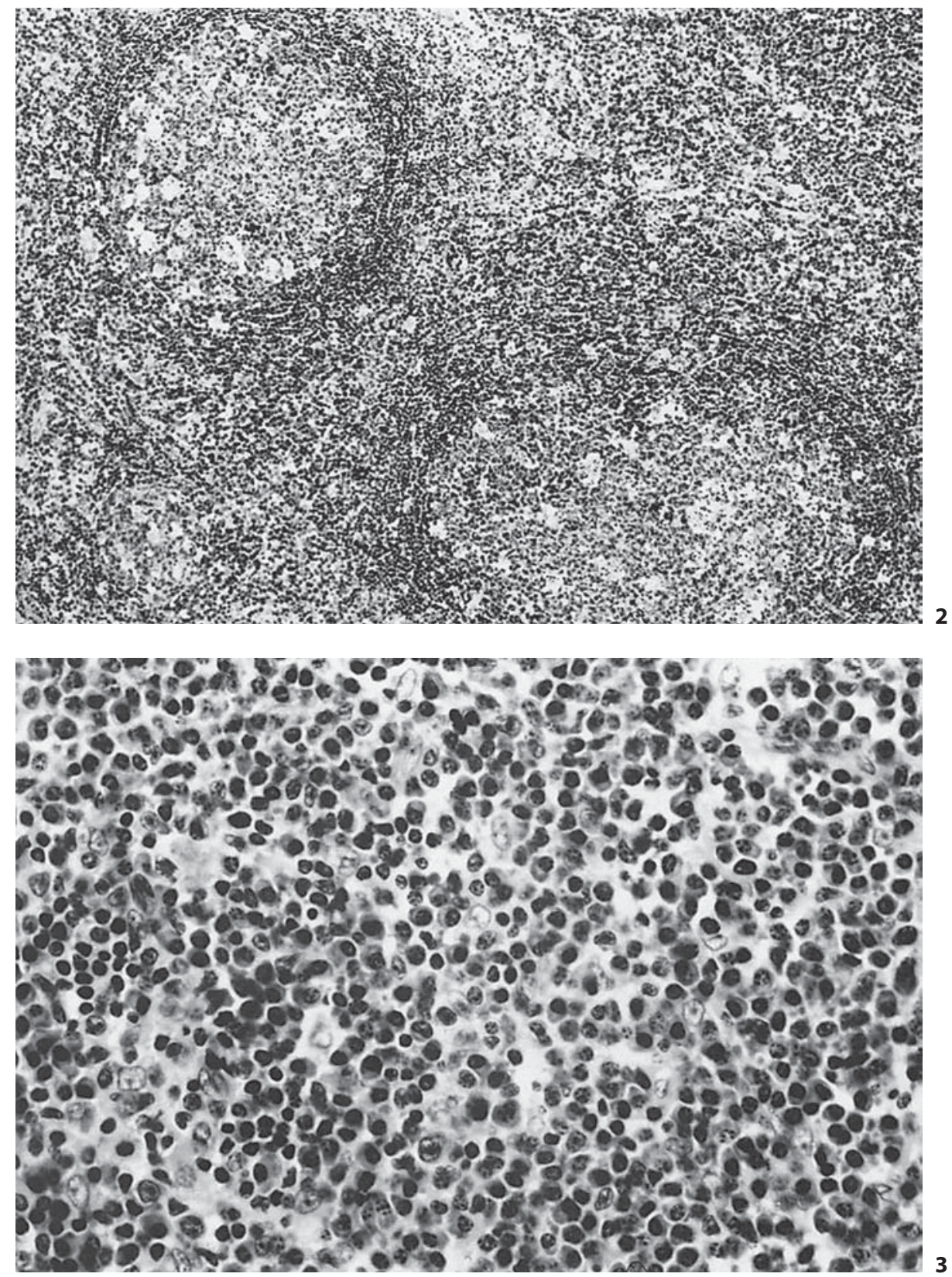

\section{Case Report}

A 53-year-old woman presented at the Neurosurgical Clinic, Ibn Sina Hospital, Kuwait, with severe headache for a few months. It was insidious in onset but followed a progressive course associated with vomiting, blurring of vision and diplopia. The past medical history revealed that she had a single epileptic attack some years ago. On neurological examination, there was no cranial nerve involvement, and no motor or sensory deficits. She had bilateral papilloedema. The patient was fully conscious and oriented. Systemic and laboratory investigations did not reveal any abnormality except for a raised erythrocyte sedimentation rate of
$55 \mathrm{~mm} / \mathrm{h}$. Computerized tomography (CT) scans with and without contrast revealed a $2 \times 2.5 \mathrm{~cm}$ hyperdense soft tissue lesion in the right occipital region. This mass was dura based, markedly contrast enhancing and surrounded by extensive perifocal edema (fig. 1). There was a mild mass effect causing effacement of the right occipital horn of the lateral ventricle but no intraventricular hemorrhage. An impression of meningioma was made.

The tumor consisted of fragments of grayish-white soft tissue along with a flap of dura. The entire specimen measured $4.5 \times$ $3 \times 1 \mathrm{~cm}$. Microscopic examination revealed lymphoid tissue with prominent secondary follicles (fig. 2). Sheets of mature-appearing plasma cells occupied the interfollicular area (fig. 3) and 
occasionally overran the follicles. Russell bodies were present. Immunoperoxidase staining performed on paraffin-embedded tissue showed light chain restriction of $\kappa$ type within the plasma cells. In the underlying cortex, lymphocytes and plasma cells were present within the perivascular Virchow-Robin spaces. Focal intracellular hemosiderin pigment was also seen at the tumor-cortex interface. Periodic acid-Schiff and silver methenamine (Grocott) stains were negative for fungus. A diagnosis of plasma cell variant of CD was made.

A right occipital craniotomy was performed. At surgery, a soft, well-defined mass without a capsule was found attached to the dura mater. It was considered to be a meningioma and was completely excised. The patient recovered fully after surgery. Post-operative CT scan confirmed total removal of the mass and disappearance of the brain edema. Whole body CT scan done upon receipt of the pathology report was essentially normal. A short course of focal adjuvant radiotherapy (50 Gy) was given and the patient was followed up on an outpatient basis. The patient is well 2 years after treatment.

\section{Discussion}

Consistent with previous reports, the solitary intracranial CD in this case was considered radiologically and intraoperatively as a meningioma [4-9]. This is understandable because solitary intracranial CD is rare while meningioma is the most common dural-based lesion in adults. This supports the assertion by Johnson et al. [11] that infrequent lesions are unlikely to be considered as a differential diagnosis of a dural-based lesion intraoperatively.

Morphologically, this was a plasma cell variant of CD. This is considered unusual partly because of its solitary nature and partly because of absence of systemic symptoms. Plasma cell variant of CD tends to be multicentric and is often associated with systemic symptoms [2, 3]. The present case is apparently the 4th case of solitary intracranial plasma cell type of CD reported in the literature $[4,7,9]$. Plasmacytoma was considered as a strong differential diagnosis in this case partly because of the sheets of plasma cells and partly because of the light chain restriction. However, the presence of reactive lymphoid follicles favored CD. Other differential diagnoses include meningiomas that are rich in lymphocytes and plasma cells or associated with hypergammaglobulinemia. These were excluded because of absence of meningothelial cells or mucin in the lesion. The significance of the light chain restriction is unknown. It raises the suspicion that CD may have a malignant potential. Progression of CD to lymphoma or plasmacytoma has been reported [3].
The etiology of $\mathrm{CD}$ remains controversial. While some authors regard it as hamartomatous, others believe it is a chronic inflammatory process, possibly of infectious origin $[1,5,12]$. Many patients, including this one, with solitary intracranial CD are more than 50 years old. This suggests that the disease is more likely inflammatory than hamartomatous.

Apart from the clinical picture, intracranial CD shows a similar sex preference as meningioma. Most patients, in agreement with this case, are females. The presenting clinical symptom in this case is most likely a manifestation of an expanding intracranial mass in the occipital region. The relationship between the mass and the previous epileptic attack remains speculative.

Total surgical excision, radiotherapy or a combination of both are considered adequate for solitary intracranial CD [4-10]. The present case was managed by surgery and low dose local radiotherapy. The use of radiation therapy for a hamartomatous or inflammatory condition may appear questionable. However, the monoclonality observed in some cases, including the present one, and the reported progression of some to lymphoma or myeloma [3] may justify low dose radiotherapy after surgery as a precautionary measure. The paucity of cases does not permit adequate evaluation of the different management protocols.

\section{Conclusion}

This case serves as a reminder that solitary intracranial $\mathrm{CD}$, as indeed other rare dural-based lesions, remains a pathological and not a clinical diagnosis. 


\section{References}

$>1$ Keller AR, Hochholzer L, Castleman B: Hyaline-vascular and plasma-cell types of giant lymph node hyperplasia of the mediastinum and other locations. Cancer 1972;29:670683.

-2 Frizzera G, Peterson BA, Bayrd ED, Goldman A: A systemic lymphoproliferative disorder with morphologic features of Castleman's disease: clinical findings and clinicopathologic correlations in 15 patients. J Clin Oncol 1985;3:1202-1216.

3 Weisenburger DD, Nathwani BN, Winberg $\mathrm{CD}$, Rappaport $\mathrm{H}$ : Multicentric angiofollicullar lymph node hyperplasia. A clinicopathologic study of 16 cases. Hum Pathol $1985 ; 16: 162-172$.

$>4$ Cummings TJ, Gong JZ, Friedman AH, McLendon RE: Castleman's disease confined to the leptomeninges. Ann Clin Lab Sci 2000;30:278-282.
5 Gulati P, Sun NC, Herman BK, Said JW, Cornford ME: Isolated leptomeningeal Castleman's disease with viral particles in the follicular dendritic cells. Arch Pathol Lab Med 1998;122:1026-1029.

6 Hashimoto H, Hilda J, Nironaka Y, Sakaki T: Intracranial Castleman's disease of solitary form. Case report. J Neurosurg 1999;90: 563-566.

$>7$ Sverson GS, Harrington DS, Weisenburger $\mathrm{DD}$, McComb RD, Casey JH, Gelber BR: Castleman's disease of the leptomeninges. Report of three cases. J Neurosurg 1988;69: 283-286.
-8 Sotrel A, Castellano-Sanchez AA, Prusmack C, Birchansky S, Brathwaite C, Ragheb J: Castleman's disease in a child presenting with a partly mineralized solitary meningeal mass. Pediatr Neurosurg 2003;38:232-237.

9 Ribeiro LT, Simao GN, Matos AL, Carlotti CG Jr, Colli BO, Neder L, RiBeiro-Silva A, de Castro M, Rego E, Santos AC: Intracranial Castleman's disease presenting as hypopituitarism. Neuroradiology 2004;46:830-833.

10 Matsumura K, Nakasu S, Tanaka T, Nioka H, Matsuda M: Intracranial localized Castleman's disease. Case report. Neurol Med Chir (Tokyo) 2005;45:59-65.

11 Johnson MD, Powell SZ, Boyer PJ, Weil RJ, Moots PL: Dural lesions mimicking meningiomas. Hum Pathol 2002;33:1211-1226.

-12 Casper C: The aetiology and management of Castleman's disease at 50 years: translating pathophysiology to patient care. Br J Hematol $2005 ; 129: 3-17$. 